\title{
Expression of interleukin-11 (IL-11) and IL-11 receptor $\alpha$ in human gastric carcinoma and IL-11 upregulates the invasive activity of human gastric carcinoma cells
}

\author{
TOSHIYUKI NAKAYAMA ${ }^{1}$, AYUMI YOSHIZAKI ${ }^{1}$, SEIYA IZUMIDA $^{1}$, TOMOYUKI SUEHIRO $^{1}$, \\ SHIRO MIURA $^{1}$, TAKASHI UEMURA ${ }^{1}$, YUICHI YAKATA ${ }^{1}$, KAZUKO SHICHIJO $^{1}$, \\ SHUNICHI YAMASHITA ${ }^{2}$ and ICHIRO SEKIN ${ }^{1}$
}

Departments of ${ }^{1}$ Tumor and Diagnostic Pathology and ${ }^{2}$ Molecular Medicine, Nagasaki University

Graduate School of Biomedical Sciences, 1-12-4 Sakamoto, Nagasaki, Japan

Received August 16, 2006; Accepted November 29, 2006

\begin{abstract}
Previous investigations have shown that interleukin-11 (IL-11) and the IL-11 receptor (IL-11R) have been correlated with the regulation of tumor progression, cellular growth and differentiation in several malignant tumors. The objectives of this study were to clarify the role of IL-11 and IL-11R $\alpha$ in human gastric carcinoma. IL-11 and IL-11R $\alpha$ were studied in 73 cases of surgically resected human gastric adenocarcinomas by immunohistochemistry. The invasive activity and cell signaling pathway of gastric carcinoma cell lines were also examined. Among the 73 cases of adenocarcinoma, $53(72.6 \%)$ and 47 cases $(64.4 \%)$ showed positive staining in carcinoma cells for the IL-11 and IL-11R $\alpha$ proteins, respectively. Histologically, IL-11 expression correlated only with Lauren's classification $(\mathrm{p}<0.05)$. The expression of IL-11R $\alpha$ correlated with the grade of tumor invasion $(\mathrm{p}<0.05)$ and vessel infiltration $(\mathrm{p}<0.01)$. All of the four gastric carcinoma cell lines expressed both IL-11 and IL-11R $\alpha$ proteins in Western blot analysis. Recombinant human IL-11 (rhIL-11) promoted the migration of SCH cells by the activation of the phosphatidylinositol-3 kinase pathway. Wortmannin diminished the promotion of chemotactic motility and invasive activity by rhIL-11. These findings suggest that the IL-11/ IL-11R pathway plays an important role in the progression and the differentiation of human gastric carcinomas.
\end{abstract}

\section{Introduction}

Gastric cancer is one of the most common cancer types in the world today, in spite of the fact that its incidence has shown a

Correspondence to: Dr Toshiyuki Nakayama, Department of Tumor and Diagnostic Pathology, Nagasaki University Graduate School of Biomedical Sciences, 1-12-4 Sakamoto, Nagasaki 852-8523, Japan E-mail: toshi-n@nagasaki-u.ac.jp

Key words: interleukin-11, interleukin-11 receptor, phosphatidylinositol-3 kinase, gastric cancer gradual decline in many countries (1). The occurrence and progression of cancer is considered to be a series of genetic events affecting the structure and/or expression of a number of oncogenes, anti-oncogenes and growth factors $(2,3)$. The deep invasive carcinomas, as in gastric carcinoma, have higher rates of lymph duct and venous invasion and lymph node metastasis (4). However, the mechanism of invasion and metastasis of gastric carcinoma is not fully understood.

Interleukin-11 (IL-11) was initially cloned as a mediator of plasmacytoma cell proliferation (5) and was later found to exhibit a wide variety of biological effects in neural cells as well as in the hematopoietic and the immune systems (6). Various unique biological functions have been attributed to IL-11, although it shares gp130 as a signaling mechanism with several cytokines and growth factors, including IL-6, oncostatin M, leukemia inhibitory factor (LIF), and ciliary neurotrophic factor (CNTF) (7).

The IL-11 receptor (IL-11R) mediates the action of IL-11, a 19.1-kDa pleiotropic cytokine that was initially cloned from a bone-marrow stromal cell line (5). While the hematopoietic effects of IL-11, which include stimulation of megakaryocyte maturation and platelet production (6), and growth stimulation of $\mathrm{CD}_{34}{ }^{+}$hematopoietic progenitor cells (8), have been well studied, IL-11R has also been shown to mediate the inhibition of adipogenesis (8), stimulation of osteoclasts (9), and cytoprotection of gut mucosa (10-13). The $\alpha$ subunit of IL-11R (IL-11R $\alpha$ ) is required for high affinity binding of the ligand; on ligand binding, gp130, the subunit responsible for signal transduction, is required for the receptor complex (14). It is not known whether IL-11R $\alpha$ associated with gp130 undergoes homodimerization, as it does in the case of the IL-6 receptor, or if an additional, as yet unidentified, subunit is involved (15).

The nature of the signaling transduction systems used by IL-11R is currently under investigation. Protein kinases that have been implicated in IL-11-mediated signaling include Jak1 and Jak2 receptor-associated kinases (15-17), MAP kinase (MAPK) and the ribosomal S6 protein kinase (18), src-family tyrosine kinases including $\mathrm{p} 60^{\text {src }}$ and $\mathrm{p} 62^{\mathrm{yes}}$, and phosphatidylinositol-3 kinase (PI3K) $(19,20)$. There is also 
evidence that the signal transduction and transcription factors (STAT) 1 and STAT3 are activated by IL-11R $(15,21)$.

In this study, the expression of IL-11 and the IL-11R $\alpha$ was examined in primary human gastric adenocarcinomas. Studies were also carried out on gastric carcinoma cell lines aimed at determining the biologic functions of IL-11.

\section{Materials and methods}

Clinical materials. Normal gastric mucosa was obtained from a patient at autopsy. Tumor specimens were obtained from patients operated on at Nagasaki University Hospital between 1999 and 2004. Each tumor was assigned a histological type and a depth grading of infiltration according to the Lauren, Carneiro and Goseki classification $(22,23)$ and the Japanese Classification of Gastric Carcinoma by the Japanese Research Society for Gastric Cancer (24), based on World Health Organization classification (25). There were 73 primary human gastric adenocarcinomas, which were composed of: 19 mucosal carcinomas, 18 submucosal infiltrative carcinomas, 7 carcinomas invading proprial muscle layers, 8 carcinomas reaching the subserosa, and 20 carcinomas penetrating the serosal surface. Histologically, of the 73 primary human gastric adenocarcinomas, 3 were papillary adenocarcinomas, 14 were tubular adenocarcinomas of the well-differentiated type, 25 were tubular adenocarcinomas of the moderately differentiated type, 6 were poorly differentiated adenocarcinomas of the solid type, 11 were poorly differentiated adenocarcinomas of the non-solid type, 11 were signet-ring cell carcinomas and 3 were mucinous adenocarcinomas. There were four adenomas included as benign lesions with moderate dysplasia. Fifteen specimens of normal gastric mucosal tissue were evaluated as normal controls that were obtained from normal areas adjacent to where the tumor specimens were taken. The desmoplastic stromal reaction was graded according to the extent of the stromal area involved. It was defined as 'slight' when the fibrous stromal area was $<25 \%$ of the whole tumor), 'moderate' (between 25 and 50\%), and 'extensive' (when it exceeded $75 \%$ of the whole tumor) based on the overall pattern (26). The examination was performed on routine slides to identify lymphatic, venous and perineural invasion. Hematoxylin and eosin and the van Gieson elastic staining methods were used in all cases. Each parameter was defined as 'present' when invasion was identified with certainty, but defined as 'absent' when it was either not observed at all or not observed with certainty $(27,28)$. Lymph node metastasis was defined as 'present' only when histologically proven. Diagnosis was established by two independent pathologists (T. Nakayama and I. Sekine).

Immunohistochemical analysis. Formalin-fixed and paraffinembedded tissues were cut into 4- $\mu$ m sections, deparaffinized in xylene and rehydrated in phosphate-buffered saline. Deparaffinized sections were preincubated with normal bovine serum to prevent non-specific binding, and then incubated overnight at $4^{\circ} \mathrm{C}$ with an optimal dilution $(0.1 \mu \mathrm{g} / \mathrm{ml})$ of a primary polyclonal rabbit antibody against human IL-11 (H-169) or IL-11R $\alpha$ (N-20). Antibodies were purchased from Santa Cruz Biotechnology, Inc. (Santa Cruz, CA, USA). The slides were then incubated with an alkaline-phosphataseconjugated goat antirabbit immunoglobulin G antibody, and the reaction products were resolved using a mixture of 5-bromo-4-chloro-3-indolyl phosphate and nitroblue tetrazolium chloride (BCIP/NBT; BRL, Gaithersburg, MD, USA). Primary antibodies preabsorbed with excess recombinant IL-11 and IL-11R $\alpha$ peptides, respectively, (Santa Cruz Biotechnology, Inc.) were used as negative controls. Gastric ulcer tissue with mucosal proliferation served as the internal positive control for IL-11 and IL-11R $\alpha$ immunostaining. Analysis of the immunohistochemical staining was performed independently by two investigators (T. Nakayama and I. Sekine). IL-11 and IL-11R $\alpha$ expression was classified into three categories depending on the percentage of cells stained: ,$- 0-10 \%$ positive cells;,$+ 10-50 \%$ positive tumor cells; and ,$++>50 \%$ positive tumor cells.

Reagents and cell culture. Recombinant human IL-11 (rhIL-11) was kindly provided by Yamanouchi Pharmaceutical Co., Ltd. (Tokyo, Japan) and was diluted in cell culture medium. MKN-1, MKN-28, NUGC-3 and SCH cell lines derived from human gastric cancer were obtained from the Human Health Resources Bank (Osaka, Japan). All cell lines were maintained in RPMI-1640 (Invitrogen Corp., Carlsbad, CA, USA) supplemented with heat inactivated $10 \%$ fetal calf serum (FCS, Invitrogen Corp.) and $2 \mathrm{mM}$ glutamine (Invitrogen Corp.) and incubated at $37^{\circ} \mathrm{C}$ in a humidified atmosphere containing $5 \% \mathrm{CO}_{2}$.

Stimulations and inhibitions. The cells were first starved in medium with reduced serum for $24 \mathrm{~h}$ to reduce basal levels of the phosphorylated(p)-S6 ribosomal protein, p-p90 RSK or p-p38 MAPK before stimulation and then were stimulated with 25, 50 and $100 \mathrm{ng} / \mathrm{ml}$ recombinant human IL-11 (Yamanouchi Pharmaceutical Co., Ltd.) for all experiments. The inhibitor Wortmannin (100 nM, Sigma-Aldrich, St. Louis, MO, USA) was added $30 \mathrm{~min}$ prior to IL-11 stimulation. The inhibitors were dissolved in dimethyl sulfoxide (DMSO, Sigma-Aldrich). A DMSO concentration of $0.001 \%$ was tested on each cell and no change in function was detected when compared to untreated cells.

Western blot analysis. Western blot analysis was performed on human gastric carcinoma tissues and human gastric carcinoma cell lines. The tissues obtained at surgery were frozen immediately after tissue sampling. The tissues and the cells were then suspended in RIPA buffer $(50 \mathrm{mM}$ Tris, $150 \mathrm{mM} \mathrm{NaCl}, 1 \% \mathrm{NP}-40,1 \%$ sodium deoxycholate and $0.05 \%$ SDS, pH 7.4), broken into pieces on ice and subjected to three freeze-thaw cycles. The insoluble tissue debris was removed by centrifugation at $14,000 \mathrm{x} \mathrm{g}$ at $0^{\circ} \mathrm{C}$ for $10 \mathrm{~min}$. The cell pellets were lysed in lysis RIPA buffer containing $50 \mathrm{mM}$ Tris, $150 \mathrm{mM} \mathrm{NaCl}, 1 \% \mathrm{NP} 40$ and $0.25 \%$ sodium deoxycholate. The cells were then cleared by centrifugation at $14,000 \mathrm{x} \mathrm{g}$ at $0^{\circ} \mathrm{C}$ for $10 \mathrm{~min}$ and sample buffer was added. The supernatant was collected and the protein concentration was quantified using a protein assay reagent (Bio-Rad Laboratories, Hercules, CA, USA). After boiling, the proteins (20 $\mu \mathrm{g})$ were separated by polyacrylamide gel electrophoresis (PAGE) under denaturing and reducing conditions, and transferred 
to a Hybond ECL nitrocellulose membrane (Amersham Pharmacia Biotech, Arlington Height, IL). The membranes were rinsed in TBS, blocked with 5\% low-fat dried milk in TBS containing $0.1 \%$ Tween-20 (TBS-T), and then incubated for $1 \mathrm{~h}$ at room temperature with a 1:500 dilution of the anti-human IL-11 or IL-11R $\alpha$ antibody (Santa Cruz Biotechnology, Inc.) and with a 1:1,000 dilution of the p-S6 ribosomal protein (Ser235/236), p-p90 RSK (Ser380) or p-p38 MAPK (Thr180/Tyr182) antibodies (Cell Signaling Technology, Beverly, MA, USA). The anti-human ß-tubulin antibody (Santa Cruz Biotechnology, Inc.) was used as an indicator for the amount of loading proteins. After extensive washing with TBS-T, the membranes were incubated for $1 \mathrm{~h}$ with a 1:1,000 dilution of the horseradish-peroxidase-conjugated donkey anti-rabbit immunoglobulin G (Santa Cruz Biotechnology, Inc.) in TBS-T containing 3\% low-fat dried milk. The membranes were washed and developed with a horseradish peroxidase chemiluminescence detection reagent (ECL Plus System, Amersham Pharmacia Biotech), and then exposed to Hyperfilm ECL (Amersham Pharmacia Biotech).

Cell growth. The cells were seeded in 6-well dishes (Corning Inc., Corning, NY, USA) at $1 \times 10^{4}$ cells per well and cultured in RPMI-1640 containing 0.5\% FCS with/without the presence of rhIL-11 (50 ng/ml, Yamanouchi Pharmaceutical Co., Ltd.). Normal rabbit IgG at the same concentration was used as a control for IL-11. To examine growth stimulation by IL-11, the medium was changed every 2 days and the number of cells and viability were counted every 2 days using a conventional improved Neubauer hemocytometer (Bright-Line; American Optical Corp. Buffalo, NY, USA). A single, experienced technologist was responsible for all manual cell counting (29).

Migration/chemotaxis assay. A 0.1-ml aliquot of SCH cell suspension at $1 \times 10^{5}$ cells $/ \mathrm{ml}$ was seeded on the upper chamber of transwell filters ( $8-\mu \mathrm{m}$ pore) (Corning Inc.), which was transferred to wells containing buffer with rhIL-11 protein or wortmannin. FCS-containing medium was added to the lower chamber and incubated for $18 \mathrm{~h}$ at $37^{\circ} \mathrm{C}$. Non-migrating cells that remained on the upper surface of the filter were removed, and the migrated cells on the lower surface of the filter were fixed with $100 \%$ methanol and stained. Five different fields were counted with a light microscope (Nikon E400) at magnification x200. All assays were performed in triplicate.

Matrigel invasion assay. The Matrigel invasion assay was carried out according to the manufacturer's instructions (BD Biosciences, Palo Alto, CA, USA). A 0.5-ml aliquot of SCH cell suspension at $1 \times 10^{5}$ cells $/ \mathrm{ml}$ was seeded on the upper chamber of Matrigel-coated transwell filters ( $8-\mu \mathrm{m}$ pore) which were transferred to wells containing buffer with rhIL-11 protein, FCS or wortmannin. Preliminary experiments showed that no cytotoxicity occurred at these concentrations as inspected under the microscope or by the trypan blue exclusion test. Control cultures received only the vehicle $(0.001 \%$ DMSO). Conditioned medium without serum was added to the lower chamber and incubated for $72 \mathrm{~h}$. Non-invading cells that remained on the upper surface of the filter were removed, and the cells that appeared on the lower surface of


Figure 1. Immunohistochemical staining of IL-11 and IL-11R $\alpha$ in gastric carcinoma tissue. IL-11 protein expressed in gastric carcinoma and localized in the cytoplasm (A). IL-11R $\alpha$ protein was localized in the membrane and the cytoplasm of carcinoma cell (B). A, x100, DAB staining; B, x100, alkalinephosphatase staining.

the filter were fixed with $100 \%$ methanol, stained and counted as described for the migration/chemotaxis assay. Each assay was carried out in triplicate.

Statistical analysis. The StatView II program (Abacus Concepts, Inc., Berkeley, CA, USA) was used for statistical analyses. Analyses comparing the degrees of IL-11 or IL-11R $\alpha$ expression were performed by the Mann-Whitney and Spearman tests.

\section{Results}

Expression of IL-11 and IL-11Ra in human gastric carcinoma tissue. The IL-11 protein was localized in the cytoplasm (Fig. 1A), while IL-11R $\alpha$ was localized in the membrane and the cytoplasm of cancer cells (Fig. 1B). In IL-11R $\alpha$ expression, the invasive parts of the primary tumor were intensely stained when compared with the superficial parts of the tumor in almost all cases of invasive carcinomas. However, there was no specific distribution of IL-11 expression in invasive carcinoma tissue. In many cases, both IL-11 and IL-11R were expressed in the carcinoma cell itself.

The immunohistochemical results are summarized in Tables I and II. IL-11 and IL-11R $\alpha$ were expressed in human 
Table I. IL-11 and IL-11R $\alpha$ expression in gastric adenocarcinoma and adenoma (83 cases), n (\%).

\begin{tabular}{|c|c|c|c|c|c|c|c|}
\hline & & & IL-11 & & & $-11 R \alpha$ & \\
\hline & $\mathrm{n}$ & - & + & ++ & - & + & ++ \\
\hline \multirow[t]{2}{*}{ Tubular adenoma } & & n.s. & \multicolumn{5}{|c|}{$\mathrm{p}=0.003054^{\mathrm{b}}$} \\
\hline & 10 & $2(20.0)$ & $4(40.0)$ & $4(40.0)$ & $8(80.0)$ & $2(20.0)$ & $\begin{array}{ll}0 & (0.0)\end{array}$ \\
\hline Total carcinoma & 73 & $20(27.4)$ & $11(15.1)$ & $42(57.5)$ & $26(35.6)$ & $13(17.8)$ & $34(46.6)$ \\
\hline \multicolumn{5}{|l|}{ Differentiation (1) } & \multicolumn{3}{|l|}{ n.s. } \\
\hline Papillary & 3 & $1(33.3)$ & $1(33.3)$ & $1(33.3)$ & $0 \quad(0.0)$ & $2(66.7)$ & $1(33.3)$ \\
\hline Tubular/well & 14 & $\begin{array}{ll}0 & (0.0)\end{array}$ & $2(14.3)$ & $12(85.7)$ & $6(42.9)$ & $1 \quad(7.1)$ & $7(50.0)$ \\
\hline Tubular/moderate & 25 & $7(28.0)$ & $3(12.0)$ & $15(60.0)$ & $8(32.0)$ & $6(24.0)$ & $11(44.0)$ \\
\hline Poor/solid & 6 & $1(16.7)$ & $\begin{array}{ll}0 & (0.0)\end{array}$ & $5(83.3)$ & $1(16.7)$ & $2(33.3)$ & $3(50.0)$ \\
\hline Poor/nonsolid & 11 & $5(45.5)$ & $1 \quad(9.1)$ & $5(45.5)$ & $3(27.3)$ & $\begin{array}{ll}0 & (0.0)\end{array}$ & $8(72.7)$ \\
\hline Signet-ring cell & 11 & $5(45.5)$ & $4(36.4)$ & $2(18.2)^{\mathrm{a}}$ & $6(54.5)$ & $1 \quad(9.1)$ & $4(36.4)$ \\
\hline Mucinous & 3 & $1(33.3)$ & $\begin{array}{ll}0 & (0.0)\end{array}$ & $2(66.7)$ & $2(66.7)$ & $1(33.3)$ & $0 \quad(0.0)$ \\
\hline (2) & \multicolumn{3}{|c|}{$\mathrm{p}=0.04952$} & & \multicolumn{3}{|l|}{ n.s. } \\
\hline Intestinal & 42 & $8(19.0)$ & $6(14.3)$ & $28(66.7)$ & $14(33.3)$ & $9(21.4)$ & $19(45.2)$ \\
\hline Diffuse & 31 & $12(38.7)$ & $5(16.1)$ & $14(45.2)$ & $12(38.7)$ & $4(12.9)$ & $15(48.4)$ \\
\hline \multicolumn{2}{|l|}{ Depth of invasion } & \multicolumn{3}{|l|}{ n.s. } & \multicolumn{3}{|l|}{$\mathrm{p}=0.01028$} \\
\hline Mucosa & 19 & $5(26.3)$ & $4(21.1)$ & $11(57.9)$ & $12(63.2)$ & $1 \quad(5.3)$ & $7(36.8)$ \\
\hline Submucosa & 18 & $5(27.8)$ & $3(16.7)$ & $10(55.6)$ & $5(27.8)$ & $7(38.9)$ & $6(33.3)$ \\
\hline Proprial muscle & 7 & $2(28.6)$ & $\begin{array}{ll}0 & (0.0)\end{array}$ & $5(71.4)$ & $3(42.9)$ & $2(28.6)$ & $2(28.6)$ \\
\hline Subserosa & 8 & $1(12.5)$ & $1(12.5)$ & $6(75.0)$ & $2(25.0)$ & $0 \quad(0.0)$ & $6(75.0)$ \\
\hline Serosal surface & 20 & $7(35.0)$ & $3(15.0)$ & $10(50.0)$ & $4(20.0)$ & $3(15.0)$ & $13(65.0)$ \\
\hline \multicolumn{2}{|l|}{ Lymph node metastasis } & \multicolumn{3}{|l|}{ n.s. } & \multicolumn{3}{|l|}{ n.s. } \\
\hline Present & 22 & $8(36.4)$ & $3(13.6)$ & $11(50.0)$ & $5(22.7)$ & $3(13.6)$ & $14(63.6)$ \\
\hline Absent & 51 & $12(23.5)$ & $8(15.7)$ & $31(60.8)$ & $21(41.2)$ & $10(19.6)$ & $20(39.2)$ \\
\hline
\end{tabular}

${ }^{a}$ There is significant difference between signet-ring cell carcinoma and total carcinoma $(\mathrm{p}=0.03360)$. ${ }^{\mathrm{b}}$ There is significant difference between adenoma and total carcinoma in the expression of IL-11R $\alpha$.

gastric adenocarcinoma and adenoma. Normal gastric epithelium and fibroblast and endothelial cells in the stroma of tumors expressed IL-11 and IL-11R $\alpha$, although weakly. Among 10 cases of adenoma, $8(80.0 \%)$ expressed IL-11 protein. IL-11 positive staining occurred mainly in the cytoplasm. Only two cases $(20.0 \%)$ of adenoma showed positive staining for IL-11R $\alpha$ in the cell membranes. The difference of IL-11R $\alpha$ expression between adenoma and adenocarcinoma was significant $(\mathrm{p}=0.003054)$.

Histologically, the expression of IL-11 and IL-11R $\alpha$ was variable (Tables I and II). Signet-ring cell carcinomas revealed significantly lower expression of IL-11 than the other histological types $(\mathrm{p}=0.03360)$. In Lauren's classification, the expression of IL-11 was statistically higher in the intestinal type of adenocarcinomas than in the diffuse type of adenocarcinomas $(\mathrm{p}=0.04952)$. For IL-11 expression, there were no correlations in the other factors. Gastric carcinoma cells showed a statistical correlation with IL-11R $\alpha$ expression in the depth of invasion $(\mathrm{p}=0.01028)$ and the venous invasion $(\mathrm{p}=0.006219)$ (Tables I and II). No other correlations with other clinicopathological factors were detected for the expression of IL-11R $\alpha$ in gastric carcinomas.

Western blot analyses of IL-11 and IL-11Ra in human normal and gastric cacinoma tissues. The expression of the IL-11 protein, its receptor and the activation of signaling proteins in gastric carcinoma tissues were examined by Western blot analysis. The IL-11 protein was clearly detected in all of the four cases of both human gastric carcinomas and normal mucosal tissues (Fig. 2). In each of the four cases, IL-11 and gp130 protein were expressed in normal and carcinoma tissues. There was no difference in the level of expression between the normal and carcinoma tissues. IL-11R $\alpha$ was expressed both in normal and carcinoma tissues. IL-11R $\alpha$, p-S6-ribosomal protein and p-P38 MAPK in cases 2-4 and p-P90 RSK in cases 2 and 3 were more highly expressed in carcinoma tissues than in normal tissues.

Expression of IL-11, IL-11Ra and gp130 in gastric carcinoma cell lines. The expression of IL-11 protein by gastric carcinoma 
Table II. IL-11/IL-11R expression in invasive carcinoma (53 cases), n (\%).

\begin{tabular}{|c|c|c|c|c|c|c|c|}
\hline & \multirow[b]{2}{*}{$\mathrm{n}$} & \multicolumn{3}{|c|}{ IL-11 } & \multicolumn{3}{|c|}{ IL-11R $\alpha$} \\
\hline & & - & + & ++ & - & + & ++ \\
\hline Invasive carcinoma & 53 & $15(28.3)$ & $7(13.2)$ & $31(58.5)$ & $14(26.4)$ & $12(22.6)$ & $27(50.9)$ \\
\hline Desmoplastic stromal reaction & & n.s. & & & n.s. & & \\
\hline Slight & 8 & $0 \quad(0.0)$ & $1(12.5)$ & $7(87.5)$ & $4(50.0)$ & $1(12.5)$ & $3(37.5)$ \\
\hline Moderate & 25 & $7(28.0)$ & $4(16.0)$ & $14(56.0)$ & $6(24.0)$ & $8(32.0)$ & $11(44.0)$ \\
\hline Extensive & 20 & $8(40.0)$ & $2(10.0)$ & $10(50.0)$ & $4(20.0)$ & $3(15.0)$ & $13(65.0)$ \\
\hline Tumor growth pattern & & n.s. & & & n.s. & & \\
\hline Expansive & 9 & $2(22.2)$ & $2(22.2)$ & $5(55.6)$ & $1(11.1)$ & $3(33.3)$ & $5(55.6)$ \\
\hline Intermediate & 21 & $5(23.8)$ & $2(9.5)$ & $14(66.7)$ & $7(33.3)$ & $6(66.7)$ & $8(38.1)$ \\
\hline Infiltrative & 23 & $8(34.8)$ & $3(13.0)$ & $12(52.2)$ & $6(26.1)$ & $3(13.0)$ & $14(60.8)$ \\
\hline Lymphatic invasion & & n.s. & & & n.s. & & \\
\hline Present & 42 & $12(28.6)$ & $4 \quad(9.5)$ & $26(61.9)$ & $12(28.6)$ & $6(14.3)$ & $24(57.1)$ \\
\hline Absent & 11 & $3(27.3)$ & $3(27.3)$ & $5(45.5)$ & $2(18.2)$ & $6(54.5)$ & $3(27.3)$ \\
\hline Venous invasion & & n.s. & & & $\mathrm{p}=0.006219$ & & \\
\hline Present & 33 & $9(27.3)$ & $3(9.1)$ & $21(63.6)$ & $6(18.2)$ & $5(15.2)$ & $22(66.7)$ \\
\hline Absent & 20 & $6(30.0)$ & $4(20.0)$ & $10(50.0)$ & $8(40.0)$ & $7(35.0)$ & $5(25.0)$ \\
\hline
\end{tabular}

n.s., not significant.

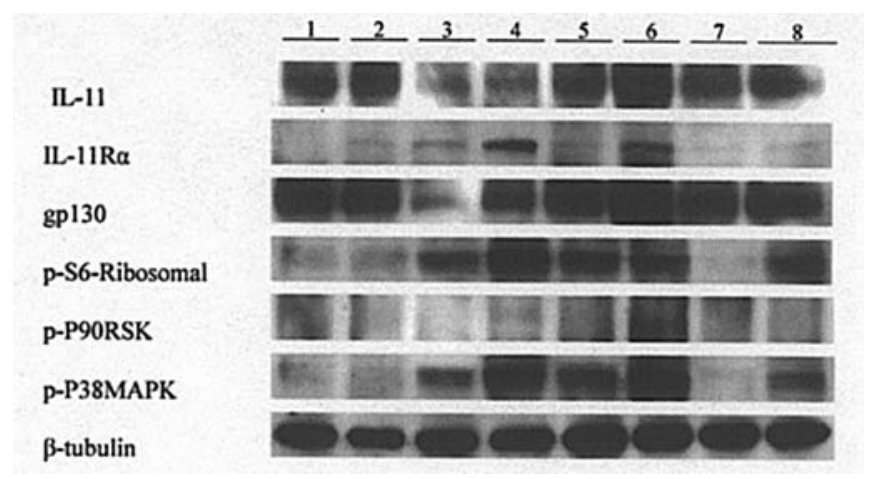

Figure 2. Expression of IL-11, IL-11R $\alpha$, gp130 and activated signaling proteins in human gastric carcinoma tissues. IL-11 and gp130 protein were expressed in gastric carcinoma and normal tissues. There was no difference in the expression level between normal and carcinoma tissues. IL-11R $\alpha$, p-S6-ribosomal protein and p-P38 MAPK in cases 2, 3 and 4 and p-P90 RSK in cases 2 and 3 were more highly expressed in carcinoma tissues than in normal tissues. Lane 1, case 1-normal mucosa; lane 2, case 1-carcinoma; lane 3, case 2-normal mucosa; lane 4, case 2-carcinoma; lane 5, case 3normal mucosa; lane 6, case 3-carcinoma; lane 7, case 4-normal mucosa; lane 8 , case 4-carcinoma.

cell lines was examined by Western blot analysis. The IL-11 protein was clearly detected in all of the four human gastric carcinoma cell lines at various levels (Fig. 3). MKN-1, MKN-28 and NUGC-3 cells expressed IL-11 at high levels, while SCH cell expressed IL-11 at a relatively low level. All four gastric carcinoma cell lines expressed IL-11R $\alpha$ and gp130 protein.

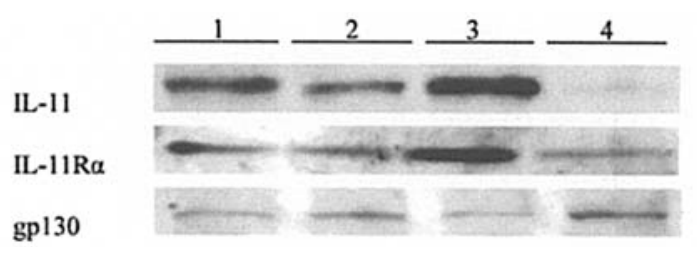

Figure 3. Expression of IL-11, IL-11R $\alpha$ and gp130 in human gastric carcinoma cell lines. The IL-11 protein was detected in all four human gastric carcinoma cell lines. MKN-1, MKN-28 and NUGC-3 cells expressed IL-11 at high levels, while SCH cell expressed IL-11 at a relatively low level. All four gastric carcinoma cell lines expressed IL-11R $\alpha$ and gp130 protein. Lane 1, MKN-1; lane 2, MKN28; lane 3, NUGC3; lane 4, SCH.

Effects of rhIL-11 on cell growth of gastric carcinoma cell lines. The effect of exogeneous IL-11 on the growth of gastric carcinoma cells was examined. MKN-28 and SCH cells were stimulated by four different doses of rhIL-11 protein. The counts of MKN28 cells revealed a progressive growth with every dose of rhIL-11 protein until the 4th day. After the 6th day, the cell numbers gradually declined and became stable (Fig. 4A). In SCH cells, the cell numbers with each dose of rhIL-11 steadly increased until the 12th day (Fig. 4B). However, there was no statistical difference in the cell growth whether the cell was treated by rhIL-11 or not in both MKN-28 and SCH cells.

Chemotaxis assays of human gastric carcinoma cells in response to rhIL-11. Transwell migration assays were performed to examine the mobilizing effect of rhIL-11 on 
A:
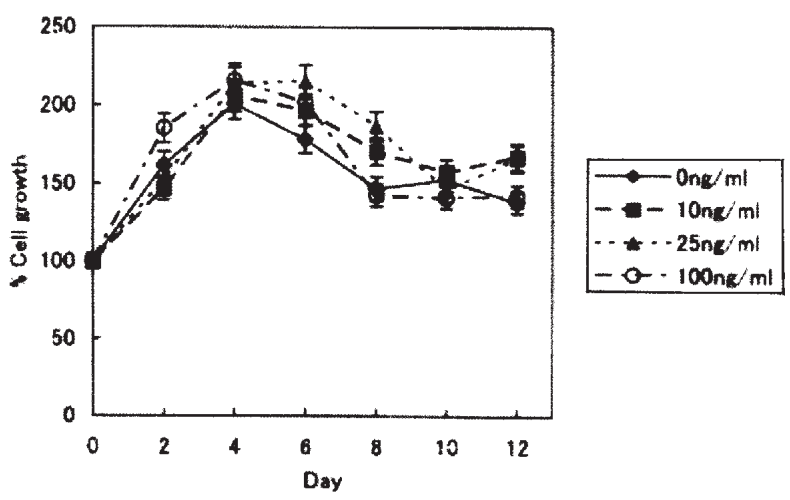

B:

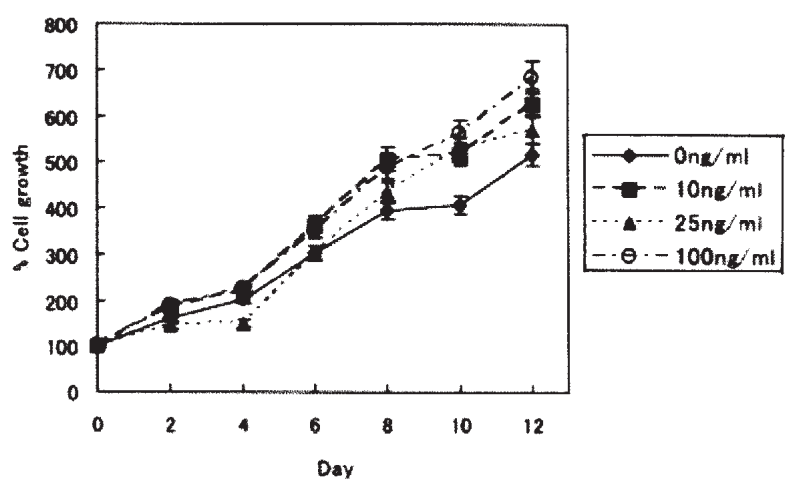

Figure 4. Proliferative effects of rhIL-11 protein in human gastric cancer cells $(\mathrm{MKN}-28$ and $\mathrm{SCH})$. The cell numbers in MKN28 grew steadily with every dose of rhIL-11 protein until 4th day. However, after the 6th day, the cell numbers were gradually reduced and became stable (A). In SCH cells, the cell numbers of each dose of rhIL-11 increased constantly until the 12th day (B). However, no clear effect of IL-11 was found in both MKN-28 and SCH cells. A, MKN-28 with $0.1 \%$ FCS; B, SCH with $0.1 \%$ FCS.

MKN28 and SCH gastric carcinoma cells. Fig. 5 shows the chemotactic response of gastric carcinoma cells to various concentrations of rhIL-11. Compared with MKN28 cells (Fig. 5A), SCH cells exhibited significant and dose-dependent chemotactic responses to rhIL-11 up to $50 \mathrm{ng} / \mathrm{ml}$ in different FCS concentrations (Fig. 5B). However, the chemotactic response to $100 \mathrm{ng} / \mathrm{ml}$ of rhIL-11 was almost the same as to $50 \mathrm{ng} / \mathrm{ml}$ of rhIL-11 in SCH cells.

Activation of signal transduction elements in response to rhIL-11 stimulation. As a first step in defining the IL-11 signalling pathway, the phosphorylation of p90RSK, p38 MAPK and S6 ribosomal protein PI3K by IL-11 was determined. The cells were stimulated with $50 \mathrm{ng} / \mathrm{ml}$ of rhIL-11 for 5 min (Fig. 6). In the two gastric carcinoma cell lines, $\mathrm{SCH}$ and $\mathrm{MKN}-28$, different reactions to signaling activation were noted. The p38MAPK was faintly phosphorylated in unstimulated cells, and rhIL-11 did not influence its phosphorylation state in both cells (Fig. 6). In SCH, MAPK and p90RSK were already phosphorylated in unstimulated cells, and rhIL-11 did not influence their phosphorylation states (Fig. 6A). The p-S6 ribosomal protein PI3K was phosphorylated after stimulation for 5 min with rhIL-11, and this activation continued for at least $1 \mathrm{~h}$ (Fig. 6A). On the other
A:


B:

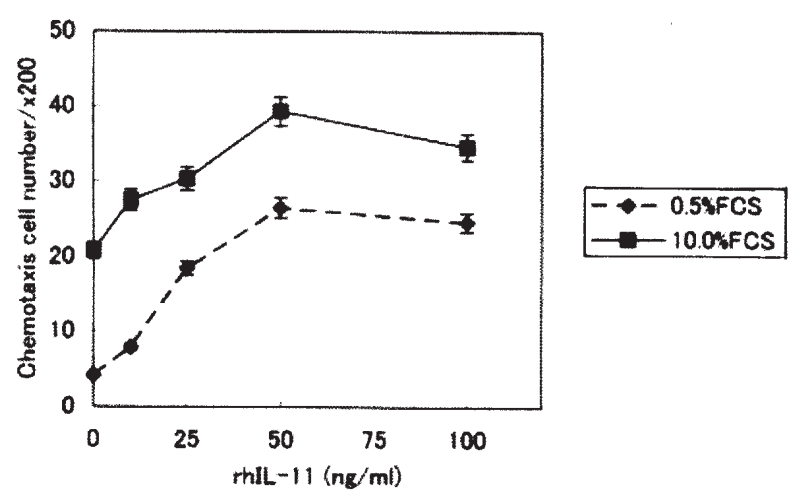

Figure 5. Chemotaxis assay in human gastric cancer cells. Transwell migration assays were performed on MKN28 and SCH gastric carcinoma cells. Compared with MKN28 (A), SCH exhibited significant and dosedependent chemotactic responses to rhIL-11 up to $50 \mathrm{ng} / \mathrm{ml}$ (B).

hand, in MKN-28, p90RSK became phosphorylated after stimulation with rhIL-11 and this activation continued for 30 min (Fig. 6B). The PI3K p-S6 ribosomal protein was faintly phosphorylated in unstimulated cells, and IL-11 did not influence its phosphorylation state (Fig. 6B).

Chemotaxis assay in SCH treated with rhIL-11 and wortmannin. To study the effect of IL-11 on the PI3K pathway in $\mathrm{SCH}$, the chemotactic response was investigated. Wortmannin, a PI3K inhibitor, suppressed chemotactic responses in $\mathrm{SCH}$ cells. The number of cells undergoing chemotaxis through a reconstituted basement membrane per five different fields is shown in Fig. 7. The $50 \mathrm{ng} / \mathrm{ml}$ of rhIL-11 upregulated the chemotactic activity of SCH cells by as much as threefold over the non-treated cells. Treatment with $100 \mathrm{nM}$ of wortmannin clearly reduced the promotive effect of rhIL-11 in the chemotaxis assay.

Invasion assay in SCH treated with rhIL-11 and wortmannin. An in vitro invasion assay was performed to investigate the effects of these chemotactic responses on the invasiveness of gastric carcinoma cells. Fig. 8 shows the number of cells that invaded through a reconstituted basement membrane per five different fields. SCH cells exhibited highly invasive responses, in a dose-dependent fashion, to rhIL-11 through the reconstituted basement membrane. To study the effect 
A:

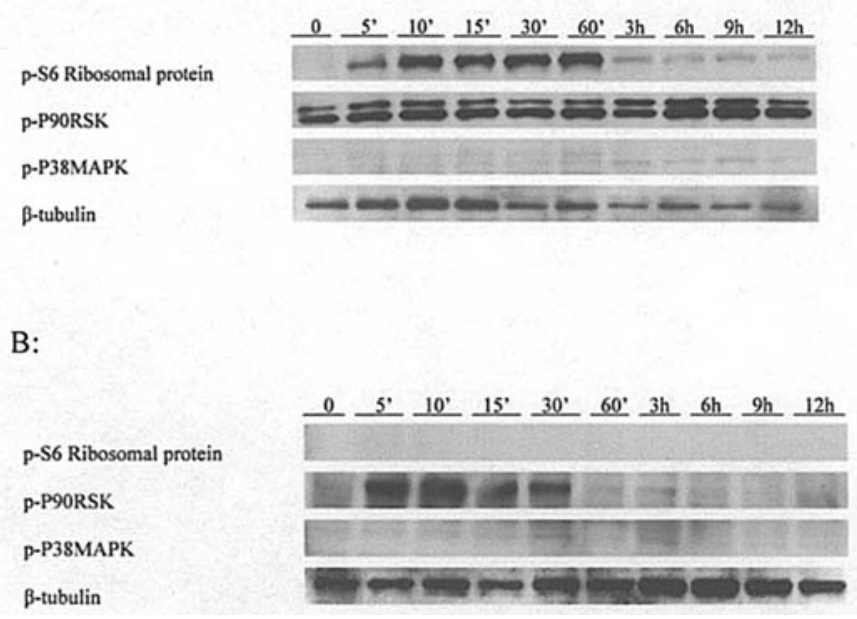

Figure 6. Signaling pathways in gastric carcinoma cell lines treated by rhIL-11. The cells were stimulated with $50 \mathrm{ng} / \mathrm{ml}$ of rhIL-11 for $5 \mathrm{~min}$. rhIL-11 did not influence the phosphorylation state of P38MAPK in both cells. In SCH, MAPK and P90RSK were phosphorylated in unstimulated cells, and rhIL-11 did not influence their phosphorylation (A). The PI3K p-S6 ribosomal protein was activated for $1 \mathrm{~h}$ (A). In MKN-28, the P90RSK was phosphorylated by rhIL-11 for $30 \mathrm{~min}$ (B). The PI3K p-S6 ribosomal protein was faintly phosphorylated in unstimulated cells, and IL-11 did not influence its phosphorylation state (B). A, SCH cell; B, MKN-28 cell.

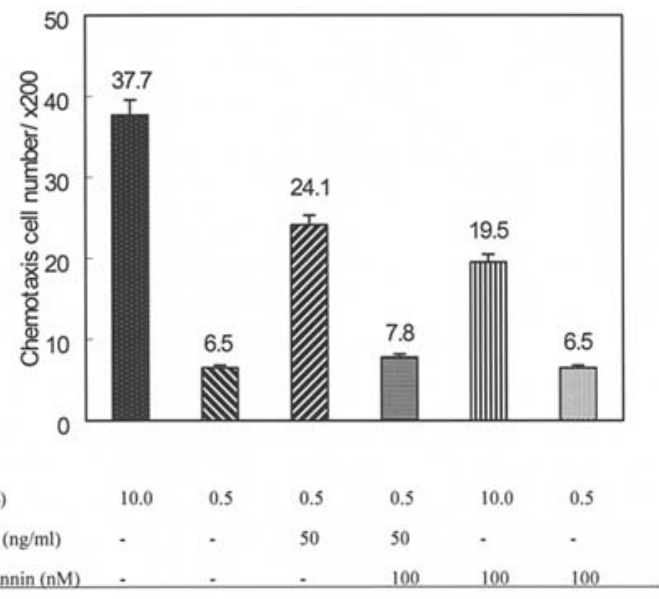

Figure 7. Chemotaxis assay in SCH treated with rhIL-11 and wortmannin. The treatment of rhIL-11 $(50 \mathrm{ng} / \mathrm{ml})$ upregulated the number of cells undergoing chemotaxis. Wortmannin $(100 \mathrm{nM})$ suppressed the chemotactic response in $\mathrm{SCH}$ cells that were upregulated by rhIL-11.

of IL-11 on the PI3K pathway in SCH cells, the effect of wortmannin, a PI3K inhibitor, on the invasive response was studied. The results showed a suppression of the chemotactic response in the SCH cells (Fig. 8).

Wortmannnin suppressed PI3K phosphorylation of gastric carcinoma cell line. To study the effect of wortmannin on the $\mathrm{PI} 3 \mathrm{~K}$ pathway in gastric carcinoma cells, $\mathrm{SCH}$ cells were preincubated with wortmannin. Phosphorylation of S6 ribosomal protein was induced by the stimulation of rhIL-11 (Fig. 8). However, wortmannin, an inhibitor of PI3K, inhibited the phosphorylation of S6 ribosomal protein in $\mathrm{SCH}$ cells.



Figure 8. Invasion assay in SCH treated with rhIL-11 and wortmannin. SCH cells exhibited highly invasive responses, in a dose-dependent fashion, to rhIL-11. Wortmannin (100 $\mathrm{nM})$ suppressed the chemotactic responses in $\mathrm{SCH}$ cells.

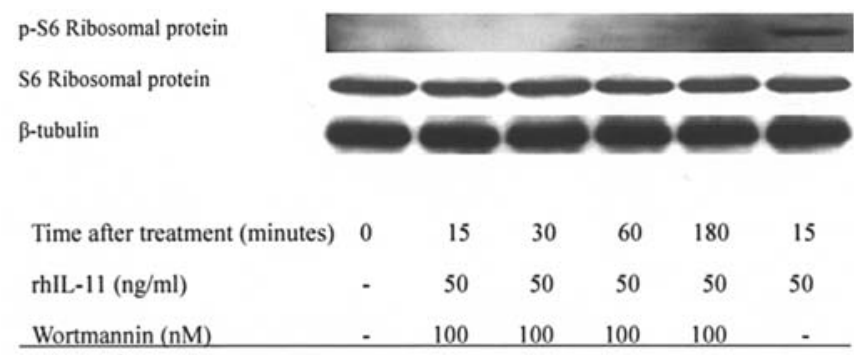

Figure 9. Wortmannnin suppressed PI3K phosphorylation of gastric carcinoma cell line. Phosphorylation of S6 ribosomal protein PI3K was induced by rhIL-11 in SCH cells. The phosphorylation of S6 ribosomal protein was inhibited by wortmannin $(100 \mathrm{nM})$.

These findings suggested that IL-11 might play an important role in migration and invasion, mediated through its signaling pathway, in gastric cancer cells.

\section{Discussion}

The expression of IL-11 has been reported in many types of cells, such as fibroblasts, chondrocytes, synovial epithelium, bronchial epithelium, and colonic epithelium (30-33). Human IL-11 has been shown to have a pleiotropic action on hematopoietic, hepatic, stromal, epithelial, neural, and osteoclast cells (34). The studies reported here demonstrate for the first time the expression of the IL-11R $\alpha$ protein in human gastric mucosa, and in gastric cancer tissues and cell lines. Also demonstrated was the constitutive expression of the IL-11 protein and the co-expression of the signal-transducing subunit gp130 in gastric carcinoma cell lines and freshly isolated gastric cancer tissues. In this study, IL-11 and IL-11R $\alpha$ were both expressed in the carcinoma cells. Therefore, the tumor cell should respond to IL-11 in an autocrine and/or paracrine fashion to stabilize itself and IL-11 may promote the invasion and the growth of tumors.

IL-11R may play a role in the invasive property of gastric carcinomas because there was a significant correlation between 
IL-11R $\alpha$ expression and invasive grade $(\mathrm{p}=0.01029)$. In those cases where the presence of venous invasion was noted, IL-11R $\alpha$ was more highly expressed ( $\mathrm{p}=0.006219)$. It appears that gastric carcinoma and its demonstrated invasive properties are consistent with what has been conceptualized in multistep carcinogenesis, a generally accepted theory with respect to cancer metastasis (35). The results reported here suggest that IL-11 has a role in stromal and venous invasion of gastric carcinoma, and constitutes one of the steps in carcinogenesis and in the development of invasive characteristics.

Histologically, the diffuse type of adenocarcinomas, which showed invasive spread, had a significantly poorer prognosis than the intestinal type $(36,37)$. In this study, a significant correlation was observed between IL-11 expression and histological differentiation of human gastric carcinoma. However, our results detected no association between IL-11R expression and tumor differentiation. Thus, our results reinforced the idea that IL-11 might play an important role in the differentiation of gastric adenocarcinoma.

IL-11R was shown to be functional, since stimulation with its cognate ligand IL-11 induced PI3K and MAPK signaling. IL-11 stimulation was followed by a rapid and transient tyrosine phosphorylation of PI3K or MAPK in the cells analyzed. Since the S6 ribosomal protein and p90RSK proteins were phosphorylated, entered the nucleus, and induced transcription of target genes $(7,38)$, signaling via the PI3K and MAPK pathways was a key event in IL-11-mediated gene regulation and downstream effects. Our data are consistent with the idea that IL-11-induced activation of signaling pathways regulates the expression of a different set of genes, depending on the cell type investigated.

The MAPK pathway is mostly known to be involved in cellular proliferation (39), although several groups have stated that in some cell types it could also be involved in cell migration (40-42). The PI3K pathway is said to be an antiapoptotic pathway in myeloma (43) although numerous groups have found that PI3K plays a key role in migration and gradient-sensing in other cell types (44-47). In our study, wortmannin, an inhibitor of the PI3K pathway, suppressed the phosphorylation of S6 ribosomal protein and reduced the invasive activity of a gastric carcinoma cell line. Thus, the activation of PI3K pathway by IL-11 may play an important role in the invasive behavior of gastric carcinoma cells.

IL-11 is known as the activator of the JAK/STAT pathway $(15,21)$. The expression of phosphorylated STATs was studied in two types of gastric carcinoma cell lines. Stimulation with IL-11 in the two cell lines resulted in only a transient phosphorylation of STATs (data not shown). However, these cell lines were different only in the nature of invasive activity. Therefore, it was concluded that the activation of the JAK/STAT pathway did not play an important role in the invasion of gastric carcinoma cells.

Recombinant human interleukin-11 (rHuIL-11, Oprelvekin, Neumega ${ }^{\circledR}$ ) was the first commercially available thrombocytopoietic cytokine (48). Some reports showed that IL-11 therapy suppressed the symptoms of diarrhea, normalized myeloperoxidase activity, and healed mucosal injury in animal models (49-51). And one report of IL-11 treatment showed the supressive effect to the symptoms of patients with Crohn's disease (52). Though this constitutes a salutary effect of
IL-11, rhIL-11 has significant side effects (53). In this study, rhIL-11 upregulated the invasive activity of carcinoma cells. While some of the data described here on IL-11 presents intriguing possibilities, considerably more progress must be made before entertaining the idea of using rhIL-11 for therapy against inflammatory bowel disease.

In conclusion, we demonstrated that the IL-11/IL-11R system regulated the activation of PI3K and MAPK pathways and upregulated the invasive activity of gastric carcinoma cells. Further identification of tyrosine kinases and/or the other pathway by IL-11 is needed to fully understand the role of this cytokine in the invasive behavior of gastric carcinoma cells.

\section{Acknowledgements}

We are grateful to Mr. Toshiyuki Kawada (Nagasaki University Graduate School of Biomedical Sciences) for his excellent immunohistochemical and molecular biological assistance.

\section{References}

1. Neugut AI, Hayek M and Howe G: Epidemiology of gastric cancer. Semin Oncol 23: 281-291, 1996.

2. Vogelstein B, Fearon ER, Hamilton SR, Kern SE, Preisinger AC, Leppert M, Nakamura Y, White R, Smits AM and Bos JL: Genetic alterations during colorectal-tumor development. N Engl J Med 319: 525-532, 1988.

3. Ming SC: Pathology of the Gastrointestinal Tract. 2nd edition. Ming SC and Goldman H (eds). Williams \& Wilkins, Baltimore, MD, pp632-633, 1998.

4. Goseki N, Koike M and Yoshida M: Histopathologic characteristics of early stage esophageal carcinoma. A comparative study with gastric carcinoma. Cancer 69: 1088-1093, 1992.

5. Paul SR, Bennett F, Calvetti JA, Kelleher K, Wood CR, O'Hara RM Jr, Leary AC, Sibley B, Clark SC, Williams DA and Yang YC: Molecular cloning of a cDNA encoding interleukin 11, a stromal cell-derived lymphopoietic and hematopoietic cytokine. Proc Natl Acad Sci USA 87: 7512-7516, 1990.

6. Du X and Williams DA: Interleukin-11: review of molecular, cell biology, and clinical use. Blood 89: 3897-3908, 1997.

7. Reddy KB, Nabha SM and Atanaskova N: Role of MAP kinase in tumor progression and invasion. Cancer Metastasis Rev 22: 395-403, 2003.

8. Keller DC, Du XX, Srour EF, Hoffman R and Williams DA: Interleukin-11 inhibits adipogenesis and stimulates myelopoiesis in human long-term marrow cultures. Blood 82: 1428-1435, 1993.

9. Sims NA, Jenkins BJ, Nakamura A, Quinn JM, Li R, Gillespie MT, Ernst M, Robb L and Martin TJ: Interleukin-11 receptor signaling is required for normal bone remodeling. $\mathrm{J}$ Bone Miner Res 20: 1093-1102, 2005.

10. Keith JC Jr, Albert L, Sonis ST, Pfeiffer CJ and Schaub RG: IL-11, a pleiotrophic cytokine: exciting new effects of IL-11 on gastrointestinal mucosal biology. Stem Cells 12 (suppl 1): 79-90, 1994.

11. Potten CS: Interleukin-11 protects the clonogenic stem cells in murine small intestinal crypts from impairment of their reproductive capacity by radiation. Int J Cancer 62: 356-361, 1995.

12. Orazi A, Du X, Yang Z, Kashai M and Williams DA: Interleukin-11 prevents apoptosis and accelerates recovery of small intestinal mucosa in mice treated with combined chemotherapy and radiation. Lab Invest 75: 33-42, 1996.

13. Kiessling S, Muller-Newen G, Leeb SN, Hausmann M, Rath HC, Strater J, Spottl T, Schlottmann K, Grossmann J, MonteroJulian FA, Scholmerich J, Andus T, Buschauer A, Heinrich PC and Rogler G: Functional expression of the interleukin-11 receptor alpha-chain and evidence of antiapoptotic effects in human colonic epithelial cells. J Biol Chem 279: 10304-10315, 2004.

14. Heinrich PC, Behrmann I, Muller-Newen G, Schaper F and Graeve L: Interleukin-6 type cytokine signaling through the gp130/Jak/STAT pathway. Biochem J 334: 297-314, 1998. 
15. Dahmen H, Horsten U, Kuster A, Jacques Y, Minvielle S, Kerr IM, Ciliberto G, Paonessa G, Heinrich PC and MullerNewen G: Activation of the signal transducer gp130 by interleukin-11 and interleukin- 6 is mediated by similar molecular interactions. Biochem J 331: 695-702, 1998.

16. Berger LC, Hawley TS, Lust JA, Goldman SJ and Hawley RG: Tyrosine phosphorylation of JAK-TYK kinases in malignant plasma cell lines growth-stimulated by interleukin 6 and 11 . Biochem Biophys Res Commun 202: 596-605, 1994.

17. Yin T, Yasukawa K, Taga T, Kishimoto T and Yang YC: Identification of a 130 kilodalton tyrosine-phosphorylated protein induced by interleukin-11 as JAK2 tyrosine kinase, which associates with gp130 signal transducer. Exp Hematol 22: 467-472, 1994.

18. Yin $\mathrm{T}$ and Yang YC: Mitogen-activated protein kinases and ribosomal S6 protein kinases are involved in signaling pathways shared by interleukin-11, interleukin-6, leukemia inhibitory factor and oncostatin $\mathrm{M}$ in mouse 3T3-L1 cells. J Biol Chem 269: 3731-3738, 1994.

19. Fuhrer DK and Yang YC: Activation of src-family protein tyrosine kinases and phosphatidylinositol-3 kinase in 3T3-L1 mouse preadipocytes by interleukin-11. Exp Hematol 24: 195-203, 1996.

20. Fuhrer DK and Yang YC: Complex formation of JAK2 with PP2A, PI3K, and yes in response to hematopoietic cytokine interleukin-11. Biochem Biophys Res Commun 224: 289-296, 1996.

21. Dimitriadis E, Stoikos C, Tan YL and Salamonsen LA: Interleukin 11 signaling components signal transducer and activator of transcription 3 (STAT3) and suppressor of cytokine sgnaling 3 (SOCS3) regulate human endometrial stromal cell differentiation. Endocrinology 147: 3809-3817, 2006.

22. Fenoglio-Preser CM, Noffsinger AE, Stemmermann GN, Lantz PE, Listrom MB and Rilke FO: The neoplastic stomach. In: Gastrointestinal Pathology. An Atras and Text. 2nd edition. Fenoglio-Preiser CM, Noffsinger AE, Stemmermann GN, Lantz PE, Listrom MB and Rilke FO (eds). Lippincott-Raven, Philadelphia, PA, pp237-274, 1999

23. Goseki N, Takizawa T and Koike M: Differences in the mode of the extension of gastric cancer classified by histological type: new histological classification of gastric carcinoma. Gut 33: 606-612, 1992.

24. Nishi M, Omori Y and Miwa K (eds): Japanese Classification of Gastric Cancer. Japanese Research Society for Gastric Cancer. Kanehara \& Co., Ltd., Tokyo, 1995.

25. Watanabe H, Jass JR and Sabin LH: Histological typing of oesophageal and gastric tumors. World Health Organization international histological classification of tumors. Springer, Berlin, pp20-26, 1989.

26. Jass JR, Atkin WS, Cuzick J, Bussey HJ, Morson BC, Northover JM and Todd IP: The grading of rectal cancer: histological perspective and a multivariate analysis of 447 cases. Histopathology 10: 437-459, 1986.

27. Seefeld PH and Bargen JA: The spread of cancer of the rectum: invasion of the lymphatics, veins and nerves. Ann Surg 118: 76-89, 1943.

28. Talbot IC, Ritchie S, Leighton M, Hughes AO, Bussey HJ and Morson BC: Invasion of veins by carcinoma of rectum: methods of detection, histological features and significance. Histopathology 5: 141-163, 1981

29. Berry MN, Edwards AM and Barritt GJ: High-yield preparation of isolated hepatocytes from rat liver. In: Isolated Hepatocytes: Preparation, Properties and Applications. Burdon RH and Knippenberg PH (eds). Elsevier, Amsterdam, pp15-58, 1991.

30. Maier R, Ganu V and Lotz M: Interleukin-11, an inducible cytokine in human articular chondrocytes and synoviocytes, stimulates the production of the tissue inhibitor of metalloproteinases. J Biol Chem 268: 21527-21532, 1993.

31. Booth C and Potten C: Effects of IL-11 on the growth of intestinal epithelial cells in vitro. Cell Prolif 28: 581-594, 1995.

32. Yang YC: Interleukin 11: an overview. Stem Cells 11: 474-486, 1993.

33. Minshall E, Chakir J, Laviolette M, Molet S, Zhu Z, Olivenstein R, Elias JA and Hamid Q: IL-11 expression is increased in severe asthma: association with epithelial cells and eosinophils. J Allergy Clin Immunol 105: 232-238, 2000.

34. Morris JC, Neben S, Bennett F, Finnerty H, Long A, Beier DR, Kovacic S, McCoy JM, Di Blasio-Smith E, La Vallie ER, Caruso A, Calvetti J, Morris G, Weich N, Paul SR, Crosier PS, Turner KJ and Wood CR: Molecular cloning and characterization of murine interleukin-11. Exp Hematol 24: 1369-1376, 1996.
35. Drewinko B, Romsdahl MM, Yang LY, Finnerty H, Long A, Beier DR, Kovacic S, McCoy JM, Di Blasio-Smith E, La Vallie ER, Caruso A, Calvetti J, Morris G, Weich N, Paul SR, Crosier PS, Turner KJ and Wood CR: Establishment of a human carcinoembryonic antigen-producing colon adenocarcinoma cell line. Cancer Res 36: 467-475, 1976.

36. Chen TR, Hay RJ and Macy ML: Karyotype consistency in human colorectal carcinoma cell lines established in vitro. Cancer Genet Cytogenet 6: 93-117, 1982.

37. Trainer DL, Kline T, McCabe FL, Faucette LF, Feild J, Chaikin M, Anzano M, Rieman D, Hoffstein S, Li DJ, Gennaro D, Buscarino C, Lynch M, Poste G and Grieg R: Biological characterization and oncogene expression in human colorectal carcinoma cell lines. Int J Cancer 41: 287-296, 1988.

38. Brader S and Eccles SA: Phosphoinositide 3-kinase signalling pathways in tumor progression, invasion and angiogenesis. Tumori 90: 2-8, 2004

39. Fang JY and Richardson BC: The MAPK signalling pathways and colorectal cancer. Lancet Oncol 6: 322-327, 2005 .

40. Bonacchi A, Romagnani P, Romanelli RG, Efsen E, Annunziato F, Lasagni L, Francalanci M, Serio M, Laffi G, Pinzani M, Gentilini P and Marra F: Signal transduction by the chemokine receptor CXCR3: activation of Ras/ERK, Src, and phosphatidylinositol 3-kinase/Akt controls cell migration and proliferation in human vascular pericytes. J Biol Chem 276: 9945-9954, 2001.

41. Delehedde M, Sergeant N, Lyon M, Rudland PS and Fernig DG: Hepatocyte growth factor/scatter factor stimulates migration of rat mammary fibroblasts through both mitogen-activated protein kinase and phosphatidylinositol 3-kinase/Akt pathways. Eur J Biochem 268: 4423-4429, 2001.

42. Tanimura S, Nomura K, Ozaki K, Tsujimoto M, Kondo T and Kohno M: Prolonged nuclear retention of activated extracellular signal-regulated kinase $1 / 2$ is required for hepatocyte growth factor-induced cell motility. J Biol Chem 277: 28256-28264, 2002.

43. Tu Y, Gardner A and Lichtenstein A: The phosphatidylinositol 3-kinase/AKT kinase pathway in multiple myeloma plasma cells: roles in cytokine-dependent survival and proliferative responses. Cancer Res 60: 6763-6770, 2000.

44. Gerszten RE, Friedrich EB, Matsui T, Hung RR, Li L, Force T and Rosenzweig A: Role of phosphoinositide 3-kinase in monocyte recruitment under flow conditions. J Biol Chem 276: 26846-26851, 2001

45. Comer FI and Parent CA: PI 3-kinases and PTEN: how opposites chemoattract. Cell 109: 541-544, 2002.

46. Curnock AP, Logan MK and Ward SG: Chemokine signalling: pivoting around multiple phosphoinositide 3-kinases. Immunology 105: 125-136, 2002

47. Stephens L, Ellson C and Hawkins P: Roles of PI3Ks in leukocyte chemotaxis and phagocytosis. Curr Opin Cell Biol 14: 203-213, 2002.

48. Demetri GD: Targeted approaches for the treatment of thrombocytopenia. Oncologist 6 (suppl 5): 15-23, 2001.

49. Greenwood-Van Meerveld B, Tyler K and Keith JC Jr: Recombinant human interleukin-11 modulates ion transport and mucosal inflammation in the small intestine and colon. Lab Invest 80: 1269-1280, 2000.

50. Du XX, Doerschuk CM, Orazi A and Williams DA: A bone marrow stromal-cell derived growth factor, interleukin-11, stimulates recovery of small intestinal mucosal cells after cytoablative therapy. Blood 83: 33-37, 1994.

51. Venkova K, Keith JC Jr and Greenwood-van Meerveld B: Oral treatment with recombinant human interleukin-11 improves mucosal transport in the colon of human leukocyte antigen-B27 transgenic rats. J Pharmacol Exp Ther 308: 206-213, 2004.

52. Herrlinger KR, Witthoeft T, Raedler A, Bokemeyer B, Krummenerl T, Schulzke JD, Boerner N, Kueppers B, Emmrich J, Mescheder A, Schwertschlag U, Shapiro M and Stange EF: Randomized, double blind controlled trial of subcutaneous recombinant human interleukin-11 versus prednisolone in active Crohn's disease. Am J Gastroenterol 101: 793-797, 2006.

53. Zhang XG, Gu JJ, Lu Z, Yasukawa K, Yancopoulos GD, Turner K, Shoyab M, Taga T, Kishimoto T, Bataille R and Klein B: Ciliary neurotropic factor, interleukin 11, leukemia inhibitory factor, and oncostatin $\mathrm{M}$ are growth factors for human myeloma cell lines using the interleukin 6 signal transducer gp130. J Exp Med 179: 1337-1342, 1994. 